\title{
Experiencing Financial Strain and Clinically Assessed Caries Experience in Dentate Adults Aged 25-44 Years: An Exploration of Potential Pathways
}

\author{
Mariëlle A. Beenackers ${ }^{a}$ Jan H. Vermaire ${ }^{b, c}$ Paula van Dommelen ${ }^{b}$ \\ Annemarie A. Schuller ${ }^{b, c}$ \\ ${ }^{a}$ Department of Public Health, Erasmus University Medical Centre, Rotterdam, The Netherlands; \\ ${ }^{b}$ Department of Child Health, TNO, Netherlands Organisation for Applied Scientific Research, \\ Leiden, The Netherlands; ' ${ }^{C}$ Centre for Dentistry and Oral Hygiene, University Medical Centre Groningen, \\ Groningen, The Netherlands
}

\section{Keywords}

Caries experience $\cdot$ Caries prediction - Diet · Epidemiology · Financial strain · Oral hygiene · Plaque index · Public dental health · Tooth brushing

\begin{abstract}
Large socioeconomic inequalities still exist in oral health. It is already known that oral health-related behaviour may contribute to these inequalities, but why people with a lower socioeconomic position behave less healthily is not easily understood. A possible explanation that integrates insights on health behaviour, stress, and financial resources is the pathway of behavioural responses to financial strain. The aim of this study was to assess to what extent financial strain is associated with clinically assessed caries experience in a population-based study of dentate adults, independently of other socioeconomic indicators. Furthermore, the potential mediating pathways of oral health-related behaviours (oral hygiene, dietary habits, preventive dental visits) were explored. Dentate participants, aged 25-44 years, taking part in a survey on oral health and preventive behaviour in the

Netherlands in 2013 were clinically examined on - among
\end{abstract}

others - caries experience (DMFS index) and level of oral hygiene (OHI-s index). Financial strain, frequency of tooth brushing, dietary habits, attendance of (preventive) dental visits in the past year, and demographic variables were assessed via questionnaires. Negative binomial hurdle models were used to study the association between financial strain and DMFS and between oral health behavioural indicators and DMFS. Although it was observed that experiencing financial strain did not seem to affect whether there is any caries experience or not, among those having any caries (DMFS $>0$ ) suffering from financial strain was associated with a higher caries prevalence, independent of educational level and income. None of the studied potential mediators could explain this association.

(c) 2020 The Author(s)

Published by S. Karger AG, Basel

\section{Introduction}

Undesired oral health conditions, like untreated dental caries and tooth loss, are very prevalent. They affected nearly 4 billion people worldwide in 2010 and accounted for a total of 15 million disability-adjusted life years [Mar-
(C) 2020 The Author(s)

Published by S. Karger AG, Basel

This is an Open Access article licensed under the Creative Commons Attribution-NonCommercial-4.0 International License (CC BY-NC) (http://www.karger.com/Services/OpenAccessLicense), applicable to the online version of the article only. Usage and distribution for commercial purposes requires written permission.
Mariëlle A. Beenackers

Department of Public Health

Erasmus University Medical Centre, PO Box 2040

NL-3000 CA Rotterdam (The Netherlands)

m.beenackers@erasmusmc.nl 
Fig. 1. Directed acyclic graph describing the potential pathways from financial strain to caries experience.

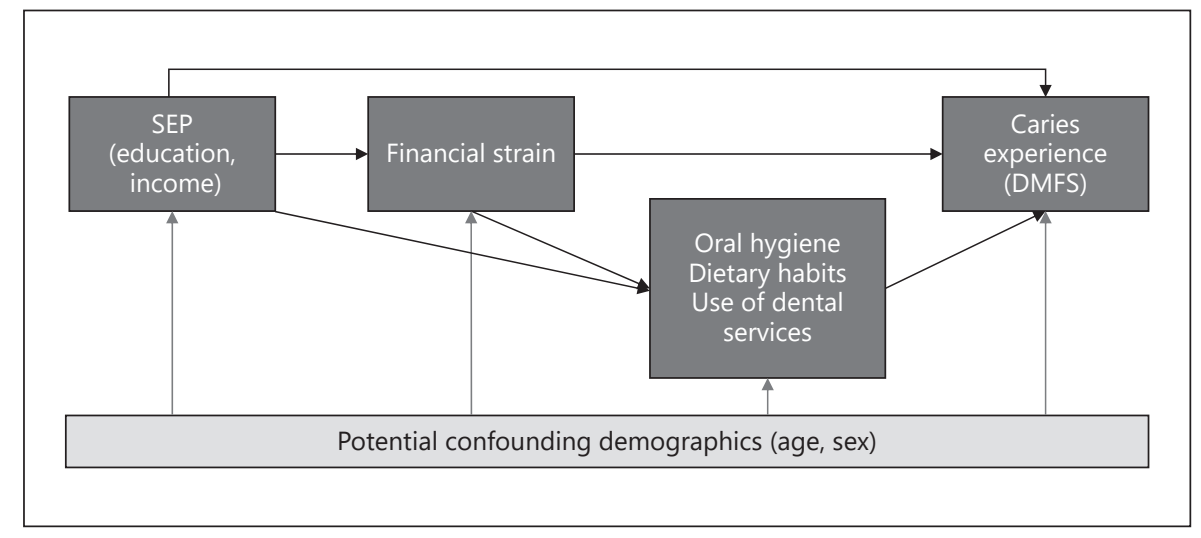

cenes et al., 2013]. Dental caries may negatively affect an individual's general health and quality of life, causing pain, masticatory and eating problems, social stigma, and accompanying social and health consequences [Petersen, 2003]. Oral diseases, with untreated caries being the most prevalent (35\% of the global population affected [Marcenes et al., 2013]), can be found throughout society. However, people with a low socioeconomic position (SEP) are affected by oral diseases disproportionately more frequently [Locker, 2000; Sanders et al., 2006a; Costa et al., 2012, 2018; Lee and Divaris, 2014; Schwendicke et al., 2015] and are therefore also affected disproportionately by their negative consequences. At the same time, people with a low SEP tend to display less attentive health behaviour, including oral health-related behaviour such as regular tooth brushing [Sanders et al., 2005; Gupta et al., 2015; Sabbah et al., 2015]. It is therefore suggested that oral health behaviours may explain the inequalities in oral health conditions [Sisson, 2007; Lee and Divaris, 2014; Sabbah et al., 2009, 2015]. However, why people with lower SEP behave less healthily is not easily understood and may rather be an expression of underlying inequalities in material and social circumstances than of conscious behavioural choices [Sisson, 2007].

Popular explanations of health inequalities state that socioeconomic inequalities in health behaviour may be influenced by a lack of knowledge or resources. Nevertheless, information-related interventions to improve oral health do not yield the desired effect and may even increase socioeconomic inequalities [Sisson, 2007]. Furthermore, oral health-promoting behaviours such as tooth brushing and limiting the frequency of consumption of fermentable carbohydrates (including sugars) are not related to high financial costs. Other mechanisms linking SEP to health behaviours and oral health are probably at play.
A possible - still underexplored - explanation that integrates pathways via behaviour, stress, and financial resources, is the pathway of behavioural responses to financial strain. Financial strain is the perceived inability to make ends meet with the disposable income (irrespective of the cause of this imbalance). Being exposed to constant feelings of stress and lack of control related to making ends meet negatively impacts health and may affect behavioural choices [Kahn and Pearlin, 2006; Tucker-Seeley et al., 2009]. The "scarcity theory" [Mani et al., 2013; Mullainathan and Shafir, 2014] implies that dealing with scarcity (such as a scarcity of money) takes up "cognitive bandwidth," i.e., "our computational capacity, our ability to pay attention, to make good decisions, to stick with our plans, and to resist temptations" [Mullainathan and Shafir, 2014, p. 41-42]. This diminished "cognitive bandwidth" may affect a person's vigilance towards oral hygiene and oral health in general as well as the use of dental services, which may increase the chances of (untreated) dental diseases [Sanders et al., 2007]. Furthermore, financial strains may cause less-desired behavioural responses such as an unhealthy diet affecting one's oral health [Shaw et al., 2011; Siahpush et al., 2014].

Therefore, the aim of this study was to assess the extent to which financial strain is associated with clinically assessed caries experience (DMFS index) in a populationbased study of dentate adults, aged 25-44 years, independently of other socioeconomic indicators. Furthermore, the potential mediating pathways of oral health-related behaviours were explored, as is visualized in the directed acyclic graph in Figure 1. We hypothesized that financial strain, independent of SEP, takes up cognitive bandwidth, which negatively affects a person's vigilance for oral hygiene, increases unhealthy dietary habits, and reduces the use of (preventive) dental services, which in turn increases the risk of caries.
Beenackers/Vermaire/van Dommelen/ Schuller 


\section{Materials and Methods}

The study population consisted of dentate adult participants aged 25-44 years taking part in a survey on oral health and preventive behaviour in the Netherlands among Dutch adults in 2013. This younger age group was chosen since they all grew up with added fluoride to their toothpaste, compared to the older age group in the study (45-74 years old). Besides that, the first possible consequences of the fact that dental care is no longer part of the basic insurance package in adulthood can be seen in the younger age groups. The purpose of this survey was to monitor oral health and oral health behaviour in adults and describe trends over time. Power calculations showed that 250 individuals in the respective age groups (25-34 and 35-44 years old) could show a statistically significant and clinically relevant difference in caries experience of $25 \%$ in $25-34$ year olds and $16 \%$ in $35-44$ year olds with previous results from $2007(\alpha=0.05$ and $\beta=0.80)$.

In the Netherlands, people are obliged to take out a health insurance in which a basic package of medical treatment is covered. All health insurance companies in the Netherlands were asked to provide names and addresses of 25-44 year olds living in 's-Hertogenbosch, a medium-sized city in the Netherlands (approx. 150,000 inhabitants) that can be considered to be representative of the Netherlands in terms of sociodemographic indicators [Statistics Netherlands, 2018a]. A random sample of 3,241 people aged 25-44 years was drawn from that database, stratified by age and SEP of the neighbourhood, to be sure that all cells regarding age and SEP would be filled at the end of the inclusion to make a representative sample of all 30,049 eligible people.

All of the selected 3,241 individuals were invited by postal letter. Upon agreement to participate in this study they returned a signed informed consent. Individuals who did not respond were contacted in person by trained interviewers who explained the purpose and importance of the study. When not found at home, a maximum of 3 additional attempts were made. Once the required number of participants was reached, further recruitment was ceased.

All participants were invited to complete a questionnaire and to come and visit a research location in their neighbourhood for a comprehensive oral health assessment. Edentulous individuals were excluded from the clinical part of the study $(n=8)$. Respectively, 217 of the 25-34 year olds and 235 of the 35-44 year olds both completed the questionnaires and participated in the clinical examination. This resulted in a sample of 452 individuals (a response of 14\%; comparable with the earlier part of the monitoring study in 2007).

The research was judged by the Central Committee on Research Involving Human Subjects (CCMO) as not falling under the Medical Research Involving Human Subjects Act. Furthermore, it was judged to meet all requirements of the Personal Data Protection Act (approval No. m1501261).

\section{Variables}

The assessment of the dependent variable comprised registration of present carious lesions and any subsequent treatment (restoration or extraction). Caries was scored at the dentine threshold (D3). Caries experience was described by the DMFS score and its components [Klein et al., 1938]. The DMFS score (sum of the number of decayed [D], missing [M], and restored [F, filled] surfaces $[\mathrm{S}]$ ) was based upon 28 teeth (third molars were excluded because of possible overestimation due to routine removal of these teeth in the previous decades). The clinical oral examinations were conducted in a mobile research facility using a mirror, a blunt probe, a halogen light source, and compressed air. Clinical assessment was performed by a team of 5 experienced and calibrated dentists. Approximately $10 \%$ of the examinations were repeated by a second examiner blinded to the results of the initial measurement. Inter-examiner agreement for DMFS was found to be high (Pearson's correlation coefficient 0.98 and intra-class coefficient 0.99) [Schuller et al., 2014, 2017].

The main exposure variable was the experience of financial strain. Financial strain was assessed by means of a questionnaire and asked whether participants had had trouble making ends meet from their household income within the past 12 months. Responses were categorized into: (1) no strain at all, (2) no strain, but had to watch expenses, or (3) financial strain.

The potential mediators included several indicators for oral health-related behaviours. Oral hygiene behaviour was assessed via self-reported tooth brushing frequency. Participants were asked to state how often they brush their teeth. Responses were dichotomized based on the recommendation to brush teeth twice a day into: (1) brushes teeth at least twice a day, and (0) brushing teeth less than twice a day.

The level of oral hygiene on the 6 index tooth surfaces was assessed using the simplified Oral Hygiene Index (OHI-s) [Greene and Vermillion, 1964]. Plaque was scored on a 4-point scale from 0 (no debris or stain) to 3 (soft debris covering more than twothirds of the exposed tooth surface), and subsequently dichotomized into: (1) OHI-s $\geq 2$, to identify those with oral hygiene concerns, and $(0)$ OHI-s $<2$.

Dietary habits were assessed by asking participants about their breakfast habits and the frequency of food and drinks per day. Participants reported the number of times a week they consumed breakfast (never, less than once a week, once a week, 2-4 times a week, 5-6 times a week [almost daily], daily). Responses were dichotomized into: (1) having breakfast 5 or more times a week, and (0) having breakfast $<5$ times a week. This dichotomization was made to distinguish respondents with healthy breakfast habits (daily or almost daily) from those with unhealthy breakfast habits, since skipping breakfast has been associated with caries [BrunoAmbrosius et al., 2005]. The total food and drink consumption were calculated based on self-reported frequency of food and drinks in the morning, the afternoon, the evening, and at night on an average weekday. Consumption of water and coffee and tea without sugar were excluded. The number of consumptions were summed and dichotomized based on the Dutch recommendations [Kruis, 2011] into: (1) food or drink consumption 7 or fewer times a day, and (0) food or drink consumption more than 7 times a day.

A proxy for the use of preventative dental services was assessed by asking participants when their last visit to the dental clinic was for a regular preventive check. This variable was dichotomized into: (1) last dental (preventive) visit within the last year, or (0) last dental (preventive) visit was over 1 year ago.

In concordance with the directed acyclic graph from Figure 1, we included the following covariates, derived from questionnaire data: age (in years), sex (male/female), educational level (dichotomized into low education [participants who had primary school or lower vocational college as their highest form of completed education] and high education [participants who had finished higher vocational college or university]), and income (below standard income, standard income, 1-2 times standard income, more than 2 
Table 1. Description of the study sample by reported financial strain

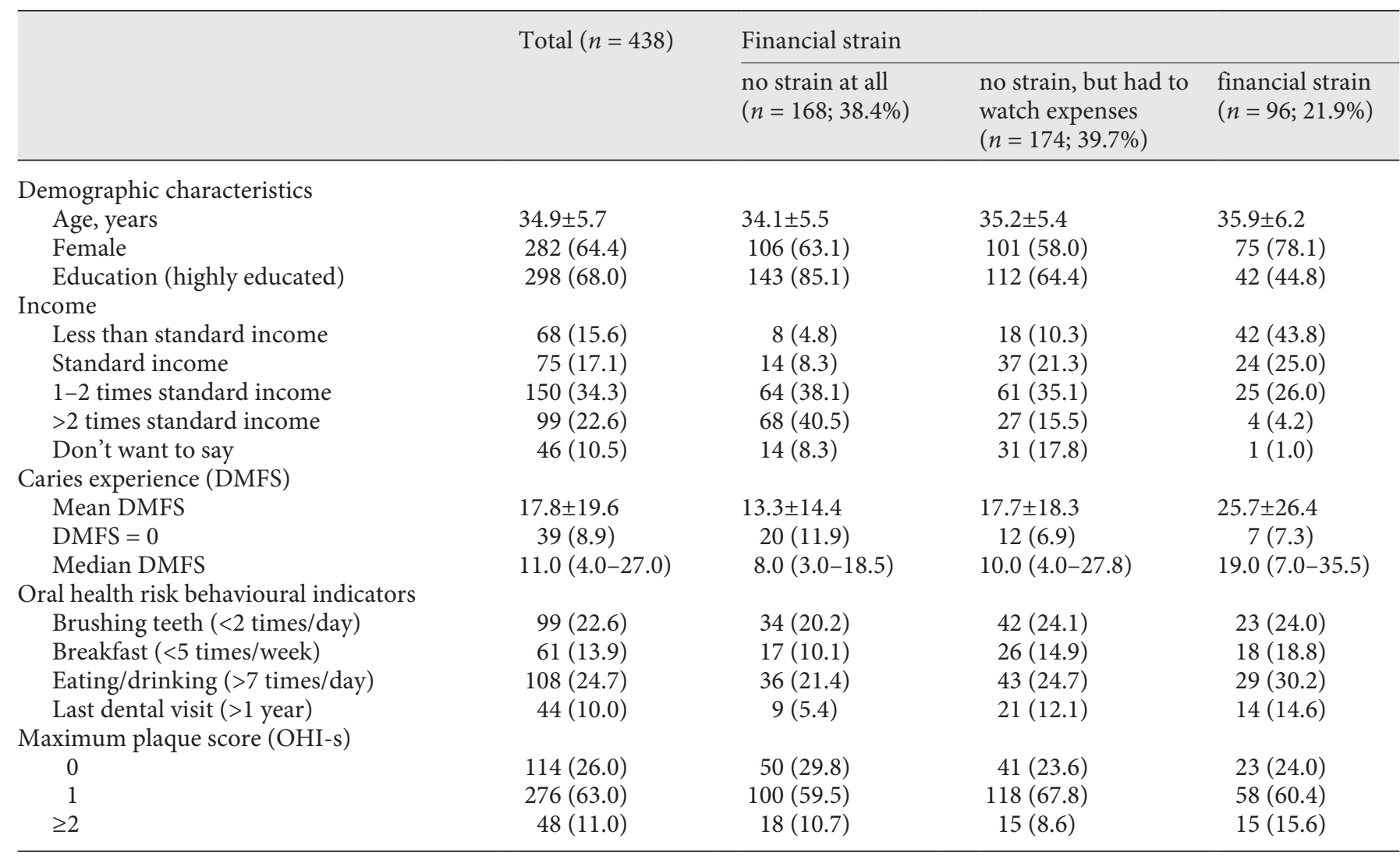

Data are presented as the mean $\pm \mathrm{SD}, n(\%)$, or the median (IQR). The DMFS score is the sum of the number of decayed (D), missing $(\mathrm{M})$, and restored (F, filled) surfaces $(\mathrm{S})$ based upon 28 teeth.

times standard income, and "I don't want to say"). The standard ("modal") yearly gross income in the Netherlands in 2013 was EUR 32,500 [Centraal Planbureau, 2014].

\section{Statistical Analyses}

Negative binomial hurdle models were used to study the association between financial strain and DMFS and between the oral health behavioural indicators and DMFS. The distribution of the DMFS index was strongly skewed with a large proportion of zeros indicating individuals with no caries experience. The negative binomial hurdle model can accommodate this specific distribution [Hofstetter et al., 2016]. The first part of the hurdle model models no caries experience (zeros) versus caries experience (non-zeros), and therefore provides odds ratios. The second part models the amount of caries experience (DMFS) within the non-zeros and therefore provides rate ratios. The first model (for both parts of the hurdle model) explored the association between financial strain and DMFS. Models 2a to 2e additionally included each of the oral health behavioural indicators. All models were adjusted for age, sex, educational level, and income. The variation inflation factor was examined to check for collinearity, especially between the socioeconomic indicators and financial strain, but no strong collinearity was detected (1.1-2.2).
The mediating role of the measured oral health risk behaviours in the association between financial strain and DMFS was checked stepwise. First, in mediation models, no exposure-mediator interaction should exist. This assumption was checked and not violated in our study, although the power to detect interactions in this sample was low. Second, the association between financial strain and the potential mediators was assessed using logistic regression models and adjusting for age, sex, educational level, and income. Third, the association between the potential mediator and DMFS was checked, adjusted for all confounders and financial strain.

\section{Results}

Table 1 shows the description of the study sample. A total of $21.9 \%$ of respondents reported financial strain. In total, $68.0 \%$ were highly educated and $73.9 \%$ reported a standard household income or more. The mean DMFS was 17.8 with $8.9 \%$ having no caries experience at all. The DMFS showed a gradient with a higher DMFS when more financial strain was experienced. The oral health risk be-
Beenackers/Vermaire/van Dommelen/ Schuller 
Table 2. Hurdle models for caries experience

a Negative binomial hurdle models for caries experience (DMFS; $n=438$ ) - zero part (having a DMFS $>0$ versus DMFS $=0$ )

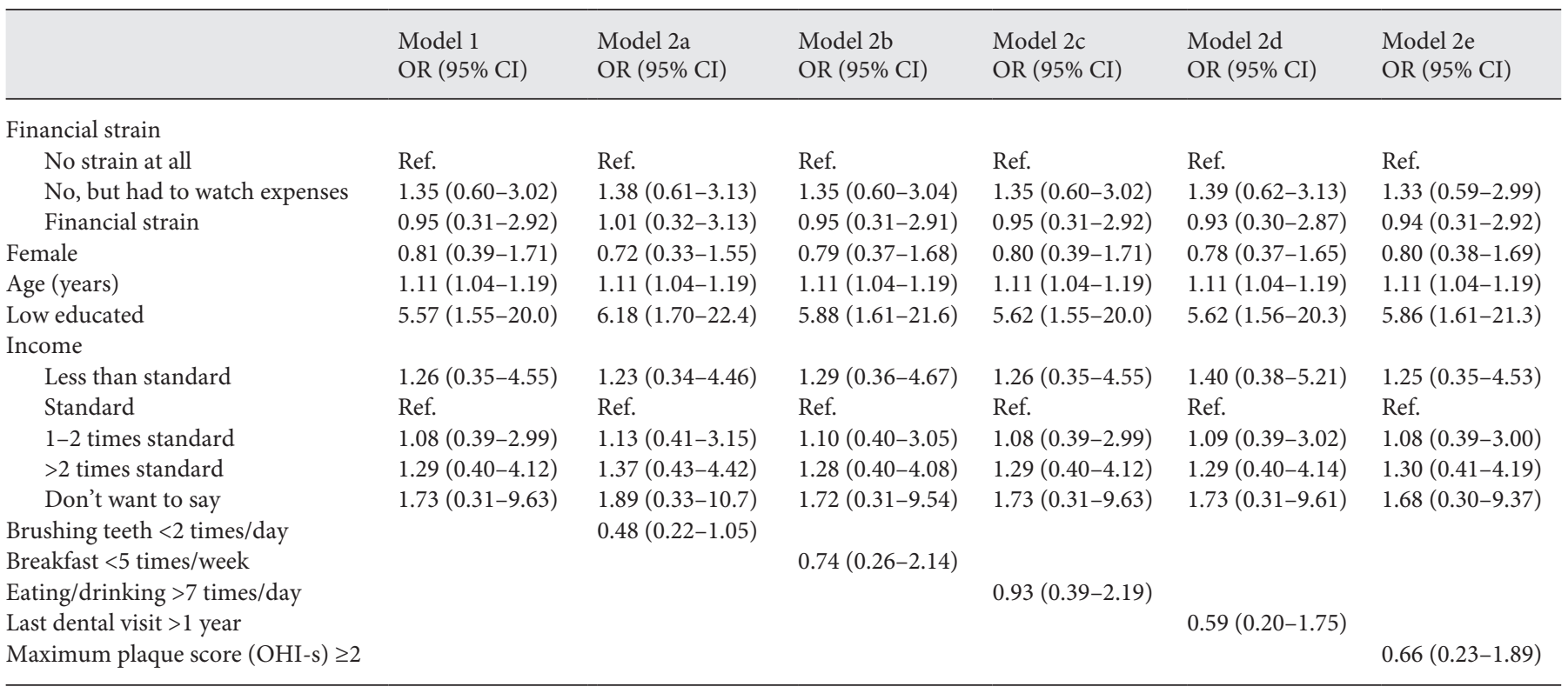

b Negative binomial hurdle models for caries experience (DMFS; $n=438$ ) - count part (amount of DMFS in those having a DMFS $>0$ )

\begin{tabular}{|c|c|c|c|c|c|c|}
\hline & $\begin{array}{l}\text { Model } 1 \\
\text { RR (95\% CI) }\end{array}$ & $\begin{array}{l}\text { Model 2a } \\
\text { RR }(95 \% \text { CI })\end{array}$ & $\begin{array}{l}\text { Model 2b } \\
\text { RR (95\% CI) }\end{array}$ & $\begin{array}{l}\text { Model 2c } \\
\text { RR }(95 \% \text { CI })\end{array}$ & $\begin{array}{l}\text { Model 2d } \\
\text { RR (95\% CI) }\end{array}$ & $\begin{array}{l}\text { Model 2e } \\
\text { RR }(95 \% \text { CI })\end{array}$ \\
\hline \multicolumn{7}{|l|}{ Financial strain } \\
\hline No strain at all & Ref. & Ref. & Ref. & Ref. & Ref. & Ref. \\
\hline No, but had to watch expenses & $1.09(0.87-1.37)$ & $1.09(0.87-1.37)$ & $1.07(0.85-1.34)$ & $1.09(0.87-1.37)$ & $1.09(0.87-1.37)$ & $1.11(0.89-1.39)$ \\
\hline Financial strain & $1.46(1.09-1.95)$ & $1.45(1.09-1.95)$ & $1.41(1.06-1.89)$ & $1.47(1.10-1.97)$ & $1.46(1.09-1.96)$ & $1.43(1.07-1.91)$ \\
\hline Female & $1.02(0.82-1.25)$ & $1.03(0.82-1.25)$ & $1.03(0.84-1.27)$ & $1.00(0.81-1.24)$ & $1.01(0.81-1.25)$ & $1.02(0.83-1.26)$ \\
\hline Age (years) & $1.05(1.03-1.07)$ & $1.05(1.03-1.07)$ & $1.05(1.03-1.07)$ & $1.05(1.03-1.07)$ & $1.05(1.03-1.07)$ & $1.05(1.03-1.07)$ \\
\hline Low educated & $1.55(1.23-1.94)$ & $1.52(1.23-1.94)$ & $1.48(1.18-1.86)$ & $1.56(1.24-1.96)$ & $1.55(1.23-1.95)$ & $1.51(1.20-1.90)$ \\
\hline \multicolumn{7}{|l|}{ Income } \\
\hline Less than standard & $1.24(0.88-1.73)$ & $1.25(0.90-1.75)$ & $1.22(0.88-1.70)$ & $1.23(0.88-1.72)$ & $1.25(0.89-1.76)$ & $1.24(0.89-1.73)$ \\
\hline Standard & Ref. & Ref. & Ref. & Ref. & Ref. & Ref. \\
\hline 1-2 times standard & $1.17(0.87-1.55)$ & $1.17(0.88-1.56)$ & $1.14(0.86-1.52)$ & $1.17(0.88-1.57)$ & $1.17(0.88-1.57)$ & $1.18(0.89-1.57)$ \\
\hline$>2$ times standard & $1.08(0.77-1.53)$ & $1.08(0.77-1.52)$ & $1.05(0.75-1.48)$ & $1.10(0.78-1.55)$ & $1.09(0.77-1.54)$ & $1.08(0.77-1.51)$ \\
\hline Don't want to say & $1.27(0.88-1.85)$ & $1.27(0.88-1.84)$ & $1.22(0.84-1.77)$ & $1.28(0.88-1.85)$ & $1.29(0.88-1.87)$ & $1.30(0.90-1.88)$ \\
\hline Brushing teeth $<2$ times/day & & $1.14(0.90-1.44)$ & & & & \\
\hline Breakfast $<5$ times/week & & & $1.40(1.07-1.83)$ & & & \\
\hline Eating/drinking $>7$ times/day & & & & $0.89(0.71-1.11)$ & & \\
\hline Last dental visit $>1$ year & & & & & $0.94(0.68-1.30)$ & \\
\hline Maximum plaque score (OHI-s) $\geq 2$ & & & & & & $1.47(1.09-1.98)$ \\
\hline
\end{tabular}

havioural indicators were prevalent between $10.0 \%$ (last dental [preventive] visit over 1 year ago) and $24.7 \%$ for consuming food or drinks more than 7 times a day. The majority of the respondents (63.0\%) had a plaque score of 1 at the time of assessment.

Financial Strain and Clinically Assessed DMFS: An Exploration of Pathways
Experiencing financial strain did not seem to affect whether there is caries experience or not (zero part of the hurdle model; Table 2a). None of the potential mediators showed a significant association with ever having experienced caries. 
Table 3. Logistic regression models for oral health risk behavioural indicators $(n=438)$

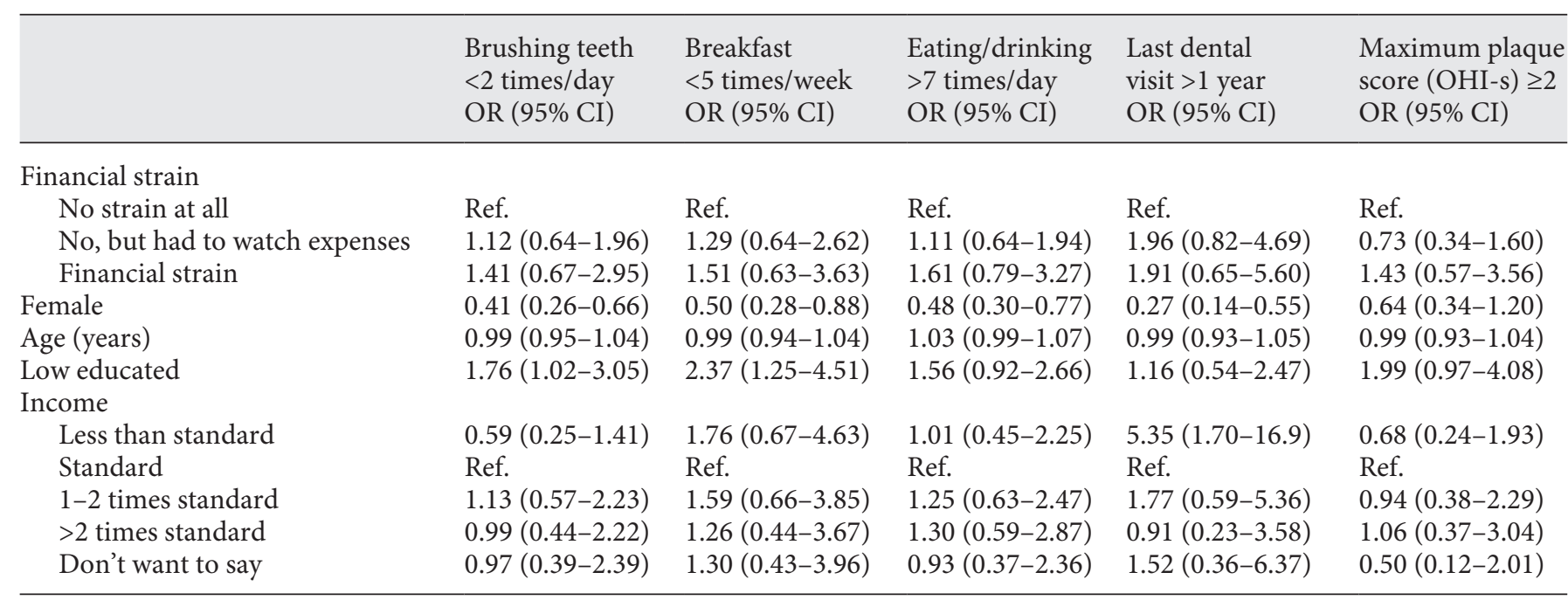

OR, odds ratio; CI, confidence interval; Ref., reference; OHI-s, Oral Health Index.

When examining the count part of the hurdle model (Table 2b), experiencing financial strain was significantly associated with a higher DMFS in those having any caries experience, independent of educational level and income. Additionally, having breakfast $<5$ times a week and having an OHI-s score of 2 or more were also associated with a higher DMFS.

Table 3 shows the results for the logistic regression models relating financial strain to the oral health risk behavioural indicators. Financial strain was not associated with any of them. Since this was a prerequisite to further explore the potential mediating role of the oral health risk behavioural indicators, further mediation analyses were not pursued.

\section{Discussion}

We hypothesized that financial strain, independent of SEP, would increase the risk of dental caries, and that this would be mediated by a less attentive level of oral hygiene, less favourable dietary habits, and less use of preventive dental services. Although it was observed that experiencing financial strain did not seem to affect whether there is any caries experience or not, we did find that among those having any caries experience, suffering financial strain was significantly associated with the DMFS score. This was independent of educational level and income. None of the studied potential mediators could explain this association.

\section{Strengths and Limitations}

A main strength of this study was the use of clinically assessed DMFS scores from a sample that included people who usually do not visit dental services (e.g., due to financial reasons or dental anxiety). Furthermore, the studied sample of adults, all aged 25-44 years, was relatively homogenous in societal characteristics that could affect oral health. They all grew up with full availability of added fluoride to toothpaste. Dental treatment was not paid for through general resources after their 18th birthday. From the age of 18 years dental treatment had to be paid out of their own pocket or through voluntary additional insurances.

However, the study should be interpreted in light of a number of limitations. First, the study was relatively small, resulting in limited power. Even though the group reporting financial strain was only small (in numbers) in our study, we still observed an association between strain and DMFS. A larger study would enable the investigation of interactions (e.g., between diet and tooth brushing) and subgroup analysis (e.g., those reporting to avoid care due to financial reasons) to further explore the potential mechanisms underlying the observed relationship.

Second, dental caries was only assessed by visual inspection. The use of X-ray photography for research purposes was not approved by the Ethics Committee. This could entail an underestimation of the absolute number of caries registrations.

Third, the study used cross-sectional associations limiting a causal interpretation of our associations. In this
Beenackers/Vermaire/van Dommelen/ Schuller 
study we hypothesized the influence of financial strain on oral health; however, due to the high costs and large outof-pocket expense of dental care in the Netherlands, poor oral health may have caused financial strain for certain people. There are many causes of financial strain (including insufficient income, excessive spending, debts, etc.) and the expectation is that, even though dental costs may have contributed to financial strain for some, this was not the reality for the majority of respondents.

Fourth, participation in the study was low and may have been selective. We therefore adjusted our models for several important personal characteristics that could have affected response, such as socioeconomic indicators. A non-response analysis showed no indication for selective response [Schuller et al., 2014] but some residual confounding or selection (e.g., because of fear) cannot be excluded. The sample was recruited in 's-Hertogenbosch, a medium-sized city in the Netherlands that can be considered representative of the national demographic profile, sociodemographic indicators, and health behaviour prevalence [Statistics Netherlands, 2018a, b].

Furthermore, by lowering the barrier to participate by using a mobile research facility in the participants' neighbourhood, clinical data could also be obtained from participants who usually do not visit dental services, resulting in a more representative sample than would have been obtained from using clinical data from dental services. Edentulous people were excluded from this research. Since edentulism is highly associated with socioeconomic deprivation [Roberto et al., 2019], this may have caused an underestimation of the association between financial strain and oral health.

\section{Interpretation of Findings}

We only observed an association between financial strain and DMFS in people who experienced caries. So far, we are unaware of any other study that investigated this particular association, but reviews of socioeconomic inequalities in caries demonstrate that caries experience is unequally distributed across population groups [Costa et al., 2012, 2018; Schwendicke et al., 2015]. Furthermore, several longitudinal studies examining exposure to socioeconomic adversity indicate a dose-response effect of socioeconomic deprivation on caries [Sabbah et al., 2015; Östberg and Petzold, 2020]. DMFS is a cumulative measure which can only increase when the duration of unfavourable oral circumstances is prolonged. Experiencing any caries or not (DMFS $=0$ or $>0$ ) may be the result of one or more shorter or longer period(s) of less than optimal oral circumstances at any stage in life after the first perma-

Financial Strain and Clinically Assessed DMFS: An Exploration of Pathways nent teeth have erupted. This dichotomous measure is therefore less sensitive to structural unfavourable circumstances compared to the cumulative count measure. The difference in nature of these 2 measures of dental caries may explain why we only observed an association between financial strain and DMFS in people who experienced any caries at all and not for ever experiencing caries.

We did not observe a significant potential mediating pathway of oral hygiene behaviour as it was not associated with financial strain. This could be an indication of the absence of this association, but it may also be due to the coarseness of the variable indicating oral hygiene behaviour: brushing teeth $<2$ times/day or not. This measure does not capture the vigilance of brushing teeth and may be susceptible to socially desirable responses. Therefore, we also included plaque score as a more objective measure of oral hygiene. Although the plaque score was associated with caries experience, no association was observed with financial strain. Differences in oral hygiene alone may not explain the association between financial strain and caries experience.

In the current study, the frequency of the consumption of food and drinks per day and having breakfast regularly were included as indicators for healthy dietary habits but neither measure mediated the association between financial strain and caries experience. The type of food is possibly also important in this relation, but unfortunately no detailed measures were available that could indicate the contents of the diet. In general, lower socioeconomic groups buy products that are less healthy [Turrell and Kavanagh, 2006; Darmon and Drewnowski, 2008; Giskes et al., 2010; Pechey et al., 2013]. A previous study indicated that financial strain may affect what people eat [Beenackers et al., 2018], although typical cariogenic dietary products were not considered. Especially sugar and other fermentable carbohydrates are well-known causes of dental caries [RuggGunn and Edgar, 1984; Burt and Pai, 2001; Bernabé et al., 2014, 2016] and a sugar-rich diet may therefore be another potential mediating pathway worthwhile of further exploration. The interactions between sugar intake and tooth brushing (with fluoride) are especially interesting since the association between sugar intake and caries is reduced to near absence when fluoride is appropriately used [van Loveren, 2019]. A prolonged exposure to a sugar-rich diet in combination with a less vigilant oral hygiene may cause more caries experience in those exposed to financial strain.

Moreover, having had a preventive dental appointment in the past year did not mediate the association between financial strain and caries experience. Dental care, including preventive care, is not included in the basic 
health insurance package for adults in the Netherlands. All consultations and treatment should be paid for directly by the patient or by an additional dental health insurance plan, mostly only partially covering the costs incurred. The association between financial strain, oral health, and preventive dental care coverage is complex. Previous research has shown that lack of dental care coverage may lead to financial strain in higher-income households, who can afford to pay out of pocket, but to an unmet need for dental care in poorer households [WHO Regional Office for Europe, 2019]. Further exploration of our sample revealed that of those who have not visited dental services for a preventive visit in the past year, half of the respondents reported that this was because of financial reasons (uninsured or too costly) and the other half reported other reasons. Unfortunately, the sample is too small to do meaningful analysis on this subgroup, warranting further research on this topic to disentangle the influence of the Dutch financing structure on financial strain and oral health.

Finally, other pathways could play a role in explaining the association between financial strain and caries experience. A possible pathway could be through elevated cortisol levels [Gomaa et al., 2019]. Financial strain may cause elevated salivary cortisol which in turn could stimulate cariogenic bacteria growth causing dental caries. Evidence is mostly from studies in children and is crosssectional [Tikhonova et al., 2018], while a cumulative exposure to stress across the lifetime and associated cortisol levels may be especially detrimental to oral health. A life course perspective could provide more in-depth understanding of the mechanisms as early life socioeconomic conditions may already weaken the teeth, making them more prone to disadvantageous circumstances later in life [Listl et al., 2018]. More research is necessary to further explore the causes of socioeconomic inequalities in health. Studies should go further than just exploring health behaviours [Sanders et al., 2006b; Sabbah et al., 2009; Watt and Sheiham, 2012] since disadvantageous circumstances and different choices and opportunities throughout the life course, such as exposure to financial strain, may contribute significantly to these inequalities and warrant a different approach than targeting individual behaviour.

\section{Conclusion}

Encountering financial strain was associated with a higher DMFS, independent of educational level and income. Potential underlying pathways should be further explored. However, since financial strain has previously been linked to health behaviours and health [Kahn and Pearlin, 2006; Krause et al., 2008; Tucker-Seeley et al., 2009; Shaw et al., 2011; Shaw et al., 2014; Siahpush et al., 2014; Beenackers et al., 2018; Lewis et al., 2018], this joint risk factor should be recognized to improve health among disadvantaged groups. Combatting poverty and an effective debt-release program could alleviate financial strain and in turn has the potential to improve both oral and overall health. More research is also needed to explore the role of the current health insurance scheme in the Netherlands on financial strain and inequalities.

\section{Statement of Ethics}

Informed consent was obtained from all participants. The research was judged by the Central Committee on Research Involving Human Subjects (CCMO) as not falling under the Medical Research Involving Human Subjects Act. Furthermore, it was judged to meet all requirements of the Personal Data Protection Act (approval No. m1501261).

\section{Conflict of Interest Statement}

The authors have no conflicts of interest to declare.

\section{Funding Sources}

M.A.B. was funded by a grant from the Netherlands Organization for Health Research and Development (grant No. 200500005). The main study was financed by the Dutch National Health Care Institute (ZIN). The funders were not involved in any process of the research. The study does not necessarily reflect the funders views and in no way anticipates the funders future policy in this area.

\section{Author Contributions}

All authors assume responsibility for the results reported in the manuscript. A.A.S. and J.H.V. were responsible for the primary data collection. M.A.B. drafted the manuscript. All authors (M.A.B., J.H.V., P.v.D., and A.A.S.) were involved in the conceptualization, analysis, and interpretation, and read and approved the final version of this manuscript. 


\section{References}

Beenackers MA, Oude Groeniger J, van Lenthe FJ, Kamphuis CB. The role of financial strain and self-control in explaining health behaviours: the GLOBE study. Eur J Public Health. 2018 Aug;28(4):597-603.

Bernabé E, Vehkalahti MM, Sheiham A, Aromaa A, Suominen AL. Sugar-sweetened beverages and dental caries in adults: a 4-year prospective study. J Dent. 2014 Aug;42(8):952-8.

Bernabé E, Vehkalahti MM, Sheiham A, Lundqvist A, Suominen AL. The shape of the doseresponse relationship between sugars and caries in adults. J Dent Res. 2016 Feb;95(2): $167-72$.

Bruno-Ambrosius K, Swanholm G, Twetman S. Eating habits, smoking and toothbrushing in relation to dental caries: a 3-year study in Swedish female teenagers. Int J Paediatr Dent. 2005 May; 15(3):190-6.

Burt BA, Pai S. Sugar consumption and caries risk: a systematic review. J Dent Educ. 2001 Oct;65(10):1017-23.

Centraal Planbureau. Macro economische verkenning 2014. CPB; 2014.

Costa SM, Martins CC, Bonfim ML, Zina LG, Paiva SM, Pordeus IA, et al. A systematic review of socioeconomic indicators and dental caries in adults. Int J Environ Res Public Health. 2012 Oct;9(10):3540-74.

Costa SM, Martins CC, Pinto MQ, Vasconcelos $\mathrm{M}$, Abreu MH. Socioeconomic factors and caries in people between 19 and 60 years of age: an update of a systematic review and meta-analysis of observational studies. Int J Environ Res Public Health. 2018 Aug;15(8): 1775.

Darmon N, Drewnowski A. Does social class predict diet quality? Am J Clin Nutr. 2008 May; 87(5):1107-17.

Giskes K, Avendano M, Brug J, Kunst AE. A systematic review of studies on socioeconomic inequalities in dietary intakes associated with weight gain and overweight/obesity conducted among European adults. Obes Rev. 2010 Jun;11(6):413-29.

Gomaa N, Tenenbaum H, Glogauer M, Quiñonez C. The biology of social adversity applied to oral health. J Dent Res. 2019 Dec;98(13): 1442-9.

Greene JC, Vermillion JR. The simplified oral hygiene index. J Am Dent Assoc. 1964 Jan;68(1): 7-13.

Gupta E, Robinson PG, Marya CM, Baker SR Oral health inequalities: relationships between environmental and individual factors. J Dent Res. 2015 Oct;94(10):1362-8.

Hofstetter H, Dusseldorp E, Zeileis A, Schuller AA. Modeling caries experience: advantages of the use of the hurdle model. Caries Res. 2016;50(6):517-26.

Kahn JR, Pearlin LI. Financial strain over the life course and health among older adults. J Health Soc Behav. 2006 Mar;47(1):17-31.

Financial Strain and Clinically Assessed DMFS: An Exploration of Pathways
Klein H, Palmer CE, Knutson JW. Studies on dental caries: I. Dental status and dental needs of elementary school children. Public Health Reports. 1938;53(10):751-65.

Krause N, Newsom JT, Rook KS. Financial strain, negative social interaction, and self-rated health: evidence from two united states nationwide longitudinal surveys. Ageing Soc. 2008;28(7):1001-23.

Kruis I. Advies cariëspreventie. Praktische handleiding voor wie professionale adviezen geeft over preventieve mondzorg [Advice on caries prevention. Practical guideline for those who give professional advice on preventive dentistry]. Zoetermeer: Ivoren Kruis; 2011.

Lee JY, Divaris K. The ethical imperative of addressing oral health disparities: a unifying framework. J Dent Res. 2014 Mar;93(3):22430.

Lewis M, Greaney SK, McGilvray MM, James AS. Examining challenges and limitations of measuring financial strain in health outcomes research: A literature review. Ann Behav Med. 2018;52:S827.

Listl S, Broadbent JM, Thomson WM, Stock C, Shen J, Steele J, et al. Childhood socioeconomic conditions and teeth in older adulthood: evidence from SHARE wave 5. Community Dent Oral Epidemiol. 2018 Feb;46(1): 78-87.

Locker D. Deprivation and oral health: a review. Community Dent Oral Epidemiol. 2000 Jun; 28(3):161-9.

Mani A, Mullainathan S, Shafir E, Zhao J. Poverty impedes cognitive function. Science. 2013 Aug;341(6149):976-80.

Marcenes W, Kassebaum NJ, Bernabé E, Flaxman A, Naghavi M, Lopez A, et al. Global burden of oral conditions in 1990-2010: a systematic analysis. J Dent Res. 2013 Jul;92(7):592-7.

Mullainathan S, Shafir E. Scarcity. London: Penguin Books Ltd; 2014.

Östberg AL, Petzold M. A longitudinal study of the impact of change in socioeconomic status on dental caries in the permanent dentition of Swedish children and adolescents. Community Dent Oral Epidemiol. 2020 Aug;48(4): 271-9.

Pechey R, Jebb SA, Kelly MP, Almiron-Roig E, Conde S, Nakamura R, et al. Socioeconomic differences in purchases of more vs. less healthy foods and beverages: analysis of over 25,000 British households in 2010. Soc Sci Med. 2013 Sep;92:22-6.

Petersen PE. The World Oral Health Report 2003: continuous improvement of oral health in the 21 st century-the approach of the WHO Global Oral Health Programme. Community Dent Oral Epidemiol. 2003 Dec;31(Suppl 1):3-23.

Roberto LL, Crespo TS, Monteiro-Junior RS, Martins AM, De Paula AM, Ferreira EF, et al. Sociodemographic determinants of edentulism in the elderly population: A systematic review and meta-analysis. Gerodontology. 2019 Dec;36(4):325-37.
Rugg-Gunn AJ, Edgar WM. Sugar and dental caries: a review of the evidence. Community Dent Health. 1984 Jul;1(2):85-92.

Sabbah W, Suominen AL, Vehkalahti MM, Aromaa A, Bernabé E. The role of behaviour in inequality in increments of dental caries among Finnish adults. Caries Res. 2015;49(1): $34-40$.

Sabbah W, Tsakos G, Sheiham A, Watt RG. The role of health-related behaviors in the socioeconomic disparities in oral health. Soc Sci Med. 2009 Jan;68(2):298-303.

Sanders AE, Slade GD, Turrell G, Spencer AJ, Marcenes W. The shape of the socioeconomic-oral health gradient: implications for theoretical explanations. Community Dent Oral Epidemiol. 2006a Aug;34(4):310-9.

Sanders AE, Slade GD, Turrell G, Spencer AJ, Marcenes W. Does psychological stress mediate social deprivation in tooth loss? J Dent Res. 2007 Dec;86(12):1166-70.

Sanders AE, Spencer AJ, Slade GD. Evaluating the role of dental behaviour in oral health inequalities. Community Dent Oral Epidemiol. 2006b Feb;34(1):71-9.

Sanders AE, Spencer AJ, Stewart JF. Clustering of risk behaviours for oral and general health. Community Dent Health. 2005 Sep;22(3): 133-40.

Schuller AA, Kempen van CPF, Vermaire JH, Poorterman J, Verlinden DA, Hofstetter H, Verrips GHW: Gebit fit, een onderzoek naar de mondgezondheid en het tandheelkundig preventief gedrag van volwassenen in nederland in 2013. Leiden: TNO; 2014.

Schuller AA, Vermaire JH, Verrips GH. Trends in cariëservaring van volwassenen in Nederland van 1995 tot 2013. Ned Tijdschr Tandheelkd. 2017 Feb;124(2):97-102.

Schwendicke F, Dörfer CE, Schlattmann P, Foster Page L, Thomson WM, Paris S. Socioeconomic inequality and caries: a systematic review and meta-analysis. J Dent Res. 2015 Jan;94(1): $10-8$.

Shaw BA, Agahi N, Krause N. Are changes in financial strain associated with changes in alcohol use and smoking among older adults? J Stud Alcohol Drugs. 2011 Nov;72(6):917-25.

Shaw RJ, Benzeval M, Popham F. To what extent do financial strain and labour force status explain social class inequalities in self-rated health? Analysis of 20 countries in the European Social Survey. PLoS One. 2014 Oct; 9(10):e110362.

Siahpush M, Huang TT, Sikora A, Tibbits M, Shaikh RA, Singh GK. Prolonged financial stress predicts subsequent obesity: results from a prospective study of an Australian national sample. Obesity. 2014 Feb;22(2):61621.

Sisson KL. Theoretical explanations for social inequalities in oral health. Community Dent Oral Epidemiol. 2007 Apr;35(2):81-8. 
Statistics Netherlands [Internet]. Kerncijfers wijken en buurten 2013. The Hague: CBS; 2018a [cited September 27, 2019]. Available from: https://opendata.cbs.nl/statline/\#/CBS/nl/ dataset $/ 82339 \mathrm{NED} /$ table? $\mathrm{dl}=27863$.

Statistics Netherlands [Internet]. Gezondheidsmonitor; regio, bevolking van 19 jaar of ouder, 2012. The Hague: CBS; 2018b [cited September 27, 2019]. Available from: https:// opendata.cbs.nl/statline/\#/CBS/nl/ dataset/82166NED/table? $\mathrm{dl}=27866$.
Tikhonova S, Booij L, D’Souza V, Crosara KT, Siqueira WL, Emami E. Investigating the association between stress, saliva and dental caries: a scoping review. BMC Oral Health. 2018 Mar; 18(1):41.

Tucker-Seeley RD, Li Y, Subramanian SV, Sorensen G. Financial hardship and mortality among older adults using the 1996-2004 Health and Retirement Study. Ann Epidemiol. 2009 Dec;19(12):850-7.

Turrell G, Kavanagh AM. Socio-economic pathways to diet: modelling the association between socio-economic position and food purchasing behaviour. Public Health Nutr. 2006 May;9(3):375-83. van Loveren C. Sugar restriction for caries prevention: amount and frequency. Which is more important? Caries Res. 2019;53(2):16875.

Watt RG, Sheiham A. Integrating the common risk factor approach into a social determinants framework. Community Dent Oral Epidemiol. 2012 Aug;40(4):289-96.

WHO Regional Office for Europe. Can people afford to pay for health care? New evidence on financial protection in Europe. Copenhagen: WHO Regional Office for Europe; 2019. 